\title{
ARTHROSCOPIC LATARJET TECHNIQUE COMBINED WITH ENDOBUTTONS: FUNCTIONAL OUTCOMES IN 26 CASES
}

\section{TÉCNICA DE LATARJET ARTROSCÓPICA COMBINADA COM ENDOBUTTONS: RESULTADO FUNCIONAL EM 26 CASOS}

\author{
Alexandre Tadeu do Nascimento ${ }^{1}$, Gustavo Kogake Claudio $^{1}$, Pedro Bellel Rocha ${ }^{1}$, Juan Pablo Zumárraga ${ }^{2}$, Olavo Pires de Camargo $^{3}$ \\ 1. Orthoservice Hospital, Shoulder and Elbow group, Sao José dos Campos, SP, Brazil. \\ 2. Universidade de São Paulo, Faculdade de Medicina, Hospital das Clinicas HCFMUSP, Orthopedics and Traumatology Institute, São Paulo, SP, Brazil. \\ 3. Universidade de São Paulo, Faculdade de Medicina, Department of Orthopedics and Traumatology, São Paulo, SP, Brazil.
}

\section{ABSTRACT}

Objective: The cause of anterior shoulder instability is not fully understood and surgical management remains controversial. The objective of this study was to evaluate the results of patients undergoing arthroscopic Latarjet procedure with endobuttons. Methods: A retrospective study of 26 patients undergoing arthroscopic Latarjet procedure with endobuttons to treat anterior shoulder instability. Patients with previous glenohumeral instability, failure of Bankart procedure or Instability Severity Index Score (ISIS) greater than or equal to 6, were included. Patients were assessed by: DASH, UCLA, Rowe, Visual Analog Scale (VAS) of pain and Short-Form 36 (SF36) scores. Correct position and consolidation of the graft were evaluated. Results: Mean age was 31.5 years (16 to 46). Preoperative duration of symptoms was 1.7 years (1 month to 10 years). Mean follow-up was 14.3 (6 to 24) months. Mean postoperative scores were: 10 points in DASH; 1.6 in VAS, where 23 (88\%) patients experienced mild pain and 3 (12\%) moderate pain; 89 in Rowe; 32 in UCLA and 78 in SF-36. Positioning of the graft was correct in 25 (96\%) cases, and was consolidated in $23(88 \%)$. We had two cases of graft fracture (7\%) and postoperative migration (7\%). Conclusion: Surgical treatment using arthroscopic Latarjet with endobuttons is safe and effective, producing good functional outcomes in patients. Level of Evidence IV, Case Series.

Keywords: Orthopedic surgery. Shoulder injuries. Arthroscopic surgery. Tendon transfer. Rehabilitation.

\section{RESUMO}

Objetivo: A causa da instabilidade anterior do ombro não é totalmente esclarecida e o tratamento cirúrgico é controverso. O objetivo deste estudo foi avaliar o resultado dos pacientes submetidos à técnica de Latarjet artroscópica com endobuttons. Métodos: Estudo retrospectivo de 26 pacientes submetidos à técnica de Latarjet artroscópica com endobuttons para tratamento de instabilidade anterior do ombro. Foram incluídos pacientes com instabilidade glenoumeral anterior, falha no procedimento de Bankart ou Instability Severity Index Score (ISIS) maior ou igual a 6. Foram avaliados mediante DASH, UCLA, Rowe, Escala Visual Analógica de dor (EVA) e pelo Short-Form 36 (SF36). Avaliamos também a posição correta e a consolidação do enxerto. Resultados: A média de idade foi de 31,5 anos (16 a 46). Os sintomas antes da cirurgia foram de 1,7 anos (1 mês a 10 anos). Seguimento médio de 14,3 (6 - 24) meses. A média dos escores pós-operatórios foi de 10 pontos no DASH; 1,6 pontos na EVA sendo 23 (88\%) dores leves e 3 (12\%) dores moderadas; Rowe de 89, UCLA de 32; SF-36 de 78. O posicionamento foi correto em 25 (96\%) casos e consolidou em 23 (88\%). Tivemos 2 casos de fratura (7\%) e de migração pós-operatória do enxerto (7\%). Conclusão: A cirurgia de Latarjet artroscópica com endobuttons é eficaz e segura, produzindo bons resultados funcionas. Nível de Evidencia IV, Série de Casos.

Descritores: Cirurgia ortopédica. Lesões do ombro. Artroscopia. Transferência tendinosa. Reabilitação.

Citation: Nascimento AT, Claudio GK, Rocha PB, Zumárraga JP, Camargo OP. Arthroscopic latarjet technique combined with endobuttons: functional outcomes in 26 cases. Acta Ortop Bras. [online]. 2018;26(5):328-31. Available from URL: http://www.scielo.br/aob.

\section{INTRODUCTION}

Patients with chronic anterior shoulder instability may show recurrent dislocation, subluxation or pain. ${ }^{1}$ Anterior glenoid bone deficiency has been reported in $22 \%$ of the first anterior traumatic dislocations of the shoulder and in up to $90 \%$ of the recurrent anterior shoulder instability. ${ }^{2}$ Over the last few years, several arthroscopic shoulder stabilization techniques have been proposed. These techniques continue to evolve, but despite progressive improvement, several studies show better results in open techniques. ${ }^{3}$ Many authors agree that plastic deformation of the capsular ligaments, ligament hyperlaxity or both, lessen the chances of success in Bankart's arthroscopic repair. ${ }^{4}$ Open Latarjet procedure has demonstrated excellent results in the treatment of recurrent shoulder instability. However, diagnosis and treatment of several lesions of bone and soft

All authors declare no potential conflict of interest related to this article.

Work conducted in the Orthoservice Hospital, Sao José dos Campos, SP, Brazil and in the Orthopedics and Traumatology Institute, Hospital das Clinicas HCFMUSP, Faculdade de Medicina, Universidade de Sao Paulo, Sao Paulo, SP, Brazil.

Correspondence: Juan Pablo Zumárraga. Rua Ovídio Pires de Campos, 333, Cerqueira Cesar, São Paulo, SP, Brasil. 05403-010. juanpzumarraga@@otmail.com 
tissue associated with instability are possible only by arthroscopy. Since the procedure became arthroscopic, the indications are clearer, the technique has evolved, and the functional results are also better. Now, this procedure is associated with the advantages of a minimally invasive surgery. ${ }^{5}$ The positioning and fixation of the coracoid is one of the main difficulties faced during surgery. Furthermore, the long learning curve, the need for specific guides and the potential risks of injuring the normal anatomical structures, made this procedure poorly adopted. ${ }^{6}$ General risks associated with the bone graft fixed to the antero-inferior margin of the glenoid using endobuttons, are comparable to the existing risks associated with any arthroscopic procedure to repair shoulder instability.

\section{MATERIALS AND METHODS}

A retrospective study was performed after we obtained the approval from the ethical committee review board from our institute. We review 26 cases of anterior shoulder instability treated with the arthroscopic Latarjet technic combined with endobuttons. Patients with previous instability of the shoulder, previous surgery, and failure of the Bankart procedure (7 cases), or with ISIS greater than or equal to 6 (19 cases) were included in the study. Patients who needed intraoperative conversion to open surgery due to difficulty in graft fixation ( 2 cases) were excluded from the study. All patients were evaluated by the Rowe, UCLA, DASH, VAS, and SF-36 scores, both preoperatively and postoperatively. Statistical analysis was performed by comparing pre and postoperative measurements with Student's t-test. Two-tailed and paired tests were used in all cases, and those with $p<0.05$ were considered significant.

\section{Operative technique}

The operative technique was based on published descriptions with adaptations. ${ }^{5-7}$ The main steps of the surgery are shown in figure 1 . The patients underwent general anesthesia, plexus block and placed in beach chair position. Surgical markings were drawn on their shoulder, including the portals $\mathrm{J}$ placed halfway in an arch between the axillary fold and the anterolateral portal. Portal $\mathrm{J}$ provides a direct view of the coracoid, while the anterolateral portal provides a better lateral view. ${ }^{5}$ The intra-articular approach begins in the posterior portal, where intra-articular inspection takes place. The anterior portal is created above the upper edge of the subscapularis tendon using a needle.
We evaluate the internal structures in search of lesions (labrum, glenoid, and tendons) using a probe in the anterior portal. Radiofrequency is used to resect the antero-inferior labrum and the medial glenohumeral ligament in the antero-inferior region of the glenoid. Following the plane of the medial glenohumeral ligament, a capsulectomy is performed to facilitate the posterior passage of the graft. After the exposion, the glenoid neck is debrided and crushed using a shaver for soft tissues and bone, preferably through the anterolateral portal. After the preparation of the glenoid bed to receive the graft, the coraco-acromial ligament is resected of its insertion in the coracoid to facilitate its superior visualization. The coracoid is then prepared using the portal $\mathrm{J}$ for visualization, the smaller pectoral muscle is disinserted, and its lower face is cleaned with extreme care to avoid injury to the brachial plexus. After this procedure, the soft tissues located on the anterior surface of the tendon are "loosened," and the axillary nerve is identified to avoid injury. Subsequently, a longitudinal split is made in the tendon and subscapularis muscle, to allow the passage of the coracoid graft. Then we pass the four guide wires ( 2 in the glenoid and 2 in the coracoid) for subsequent creation of the tunnel through which the endobuttons pass. The guidewires are placed in the glenoid using the anterior cruciate ligament $(\mathrm{ACL})$ reconstruction guide, with the point of the guide placed in the anterolateral portal and the other end in the posterior portal. The guide used should have an angle of $90^{\circ}$ to avoid invading the articular surface of the glenoid. The guide is placed in the antero-inferior region of the glenoid (Figure 2-a), where the tunnel is created, approximately $0.5 \mathrm{~cm}$ from the articular surface, passing the guidewire from posterior to anterior. The same process is repeated for the passage of the second guidewire in the glenoid, approximately $2 \mathrm{~cm}$ above the first. After the positioning of the two guidewires in the glenoid (Figure 2-b), a specific portal for allowing the passage of the tunnels and osteotomy of the coracoid (portal $\mathrm{H})^{5}$ is created, and then the two guidewires of the coracoid are passed freehanded, with a distance of approximately $2 \mathrm{~cm}$ between them (Figure 2-c). Once the four wires are positioned, tunneling is performed to allow the passage of the endobutton. We prefer to start by the lower glenoid tunnel, using a $5 \mathrm{~mm}$ cannulated drill. After the passage of the drill, keep it in the exit position, remove the guidewire and then pass a thread of prolene into the drill to move the endobutton from posterior to anterior position (Figure 3-a). Subsequent to the passage through the glenoid, the endobutton is provisionally retrieved
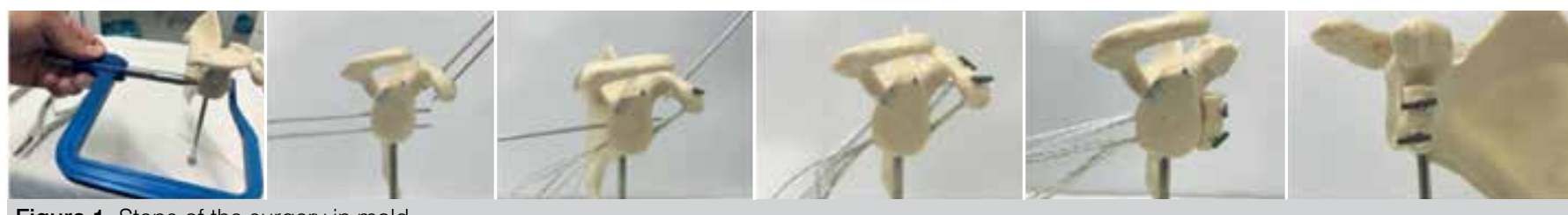

Figure 1. Steps of the surgery in mold
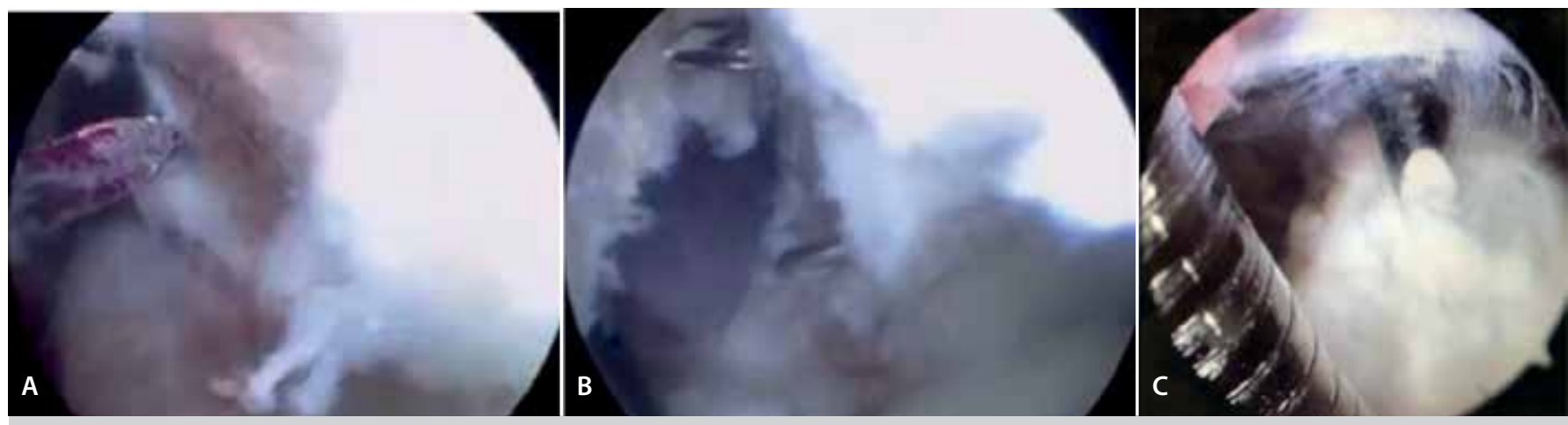

Figure 2. Arthroscopic images: Endobutton passage and the final graft appearance in the glenoid. 
to the anterolateral portal, while carefully passing it through the split of the subscapularis tendon. We then performed tunnelization of the coracoid using the most distal guidewire, retrieved the same endobutton placed on the glenoid using prolene wire in the same way, and directed it to the portal $\mathrm{H}$, passing it through the coracoid tunnel (Figure 3 -b). Consequently, the same endobutton becomes connected from the posterior region of the glenoid to the superior cortical of the coracoid. The same process is then performed on the other guidewires, connecting another endobutton from the glenoid to the coracoid. Once the two endobuttons are connected, it is possible to perform coracoid osteotomy, and then, by tractioning the endobuttons, which are connected to a single posterior button, it is possible to move the bone graft to the antero-inferior region of the glenoid, through the split in the subscapularis tendon, to the bloodshed bed (Figure 3-c). We usually use endobuttons with self-locking wires, not requiring a subsequent knot. We believe that this way we can cause greater contact force between the graft and glenoid bed.

\section{Postoperative}

The patients should use a splint for 14 days, with movements allowed according to pain. Postoperative control radiographs are taken every week (Figure 4-a) for six week, a computed tomography is required six months after surgery (Figure 4-b). They can start physical therapy for improving range of motion after two weeks and strengthening after full movement is achieved. Return to sport is allowed three months after surgery.

\section{RESULTS}

We analyzed the functional score results of 26 cases of arthroscopic Latarjet technic combined with endobutton, of which 23 were male and two female. The mean age was 31 years (16 to 46). The mean duration of symptoms was 1.7 years, ranging from 1 month to 10 years. The mean follow-up was 14 months (6 to 24). Twelve right and 14 left shoulders were operated. The mean postoperative scores were 10 points in DASH; 2 points in VAS, of which 23 (88\%) showed mild pain, and 3 (12\%) moderate pain; 89 in Rowe; 32 in UCLA; 85 in SF-36. Two patients fractured their coracoids during surgery and had the graft fixed with only one endobutton. Two patients had postoperative graft migration occurring two months after surgery; none of them had further episodes of instability. The graft consolidated in 23 (88\%) cases. We considered as consolidation, the existence of any bone bridge between the glenoid and the graft, evaluated through computed tomography. The mean distance between the lateral edge of the graft and the articular surface was $1.8 \mathrm{~mm}$, ranging from $4.7 \mathrm{~mm}$ medial to $5.2 \mathrm{~mm}$ lateral (Table 1). Only one case had a distance from the lateral surface superior to $5 \mathrm{~mm}$. In 3 cases (12\%) the graft was predominantly in the glenoid equator, while in 23 cases (88\%) the graft was predominantly below the glenoid equator. There were no cases of postoperative glenohumeral dislocation. The results showing the improvement of the Rowe, UCLA, AVS, and DASH scores are presented in table 2. We found tears associated with instability in 11 patients (42\%), of which 7 were type II superior labral anterior and posterior (SLAP) lesion treated by tenodesis of the long head of the biceps, two cases of type I SLAP lesion treated by debridement of the superior labrum, two cases of partial tear of the subscapularis and three of partial rupture of the supraspinatus, repaired using anchors. We also found two patients with circumferential labral tear. Besides undergoing the Latarjet procedure, their posterior and superior labrum were repaired. The

\begin{tabular}{c|c|c|c}
\hline Table 1. Data on the positioning of the coracoid graft. & \multicolumn{1}{l}{ No. of case } & $\%$ \\
\hline Horizontal Position & Too Medial $>5 \mathrm{~mm}$ & 0 & 0 \\
\hline & $\begin{array}{c}\text { Too lateral }>5 \mathrm{~mm} \\
\text { At the level of the } \\
\text { articular surface }\end{array}$ & 25 & 46 \\
\hline Vertical Position & $\begin{array}{c}\text { Above the glenoid equator } \\
>50 \% \text { of the graft }\end{array}$ & 0 & 0 \\
\hline & $\begin{array}{c}\text { At the level of the glenoid } \\
\text { equator }>25 \% \text { of the midline }\end{array}$ & 3 & 12 \\
\hline & Below the glenoid equator & 23 & 88 \\
\hline
\end{tabular}

\begin{tabular}{c|c|c|c|c}
\multicolumn{6}{c}{ Table 2. Results of the Rowe, DASH, UCLA, and VAS scores*. } \\
\hline & Rowe & DASH & UCLA & VAS \\
\hline \multirow{2}{*}{ Preoperative } & $31 \pm 12$ & $32 \pm 19$ & - & $6 \pm 1,8$ \\
& $(15$ to 45$)$ & $(1,7$ to 70,8$)$ & & $(2$ to 9$)$ \\
\hline \multirow{2}{*}{ Postoperative } & $89 \pm 14$ & $10 \pm 13$ & $32 \pm 2,9$ & $1,6 \pm 1,5$ \\
& $(55$ to 100$)$ & $(0$ to 40$)$ & $(26$ to 35$)$ & $(0$ to 5$)$ \\
\hline p value & $<0,01$ & $<0,01$ & NA & $<0,01$ \\
\hline
\end{tabular}

*Mean and standard deviation values, with the interval between parentheses.
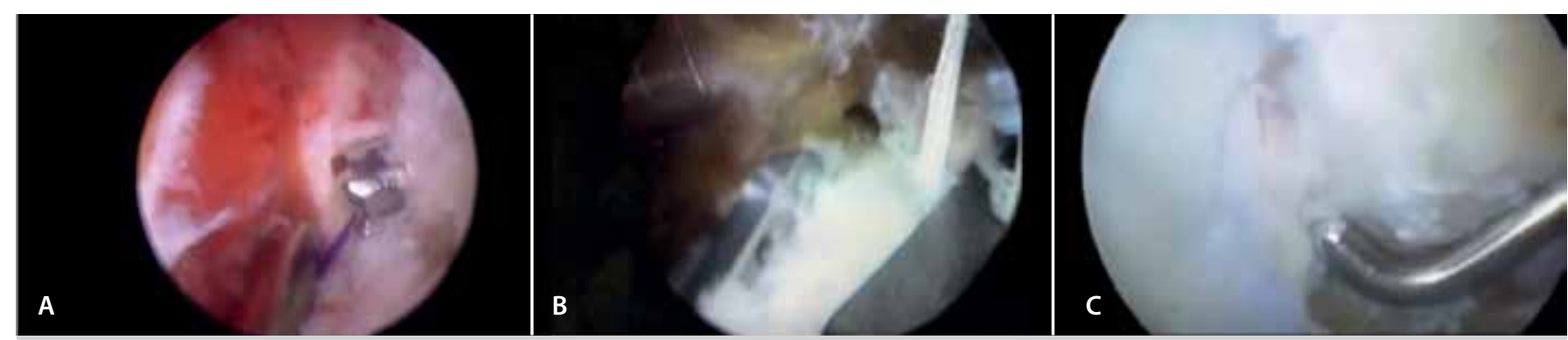

Figure 3. Arthroscopic images: passage of the guidewires
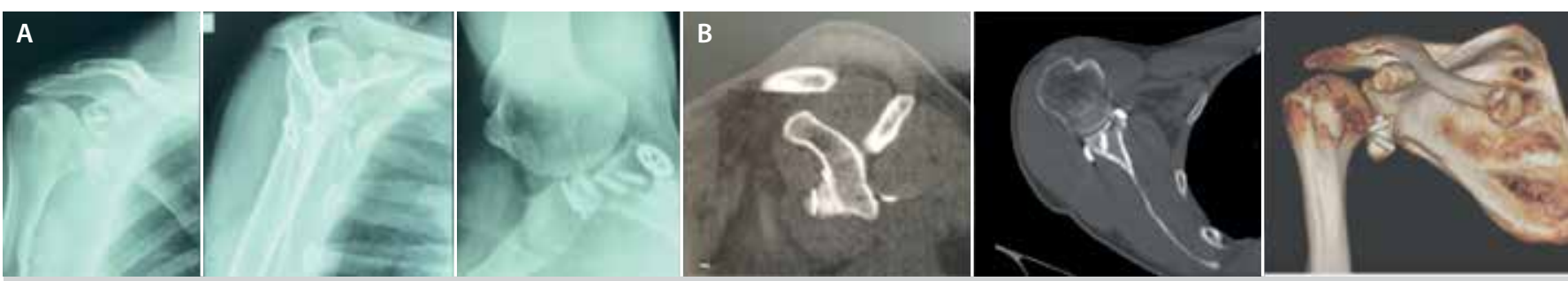

Figure 4. Complementary exams: X-rays and tomography. The patient has undergone previous Bankart repair surgery with metallic anchors. 
Table 3. Pre- and postoperative comparative results of SF-36*.

\begin{tabular}{|c|c|c|c|c|c|c|c|c|}
\hline & $\begin{array}{c}\text { Functional } \\
\text { capacity }\end{array}$ & \begin{tabular}{|c|} 
Limitations due to \\
physical aspects
\end{tabular} & Pain & $\begin{array}{c}\text { General health } \\
\text { status }\end{array}$ & Vitality & Social aspects & $\begin{array}{l}\text { Limitations due to } \\
\text { emotional aspects }\end{array}$ & Mental health \\
\hline Pre-op & $\begin{array}{c}70 \pm 17.5 \\
(30 \text { to } 100)\end{array}$ & $\begin{array}{l}26 \pm 34.2 \\
(0 \text { to } 100)\end{array}$ & $\begin{array}{l}56.6 \pm 25 \\
(22 \text { to } 90) \\
\end{array}$ & $\begin{array}{c}64.8 \pm 14.1 \\
(35 \text { to } 90) \\
\end{array}$ & $\begin{array}{l}72.9 \pm 11.6 \\
(55 \text { to } 100)\end{array}$ & $\begin{array}{l}78.4 \pm 24.8 \\
(6.5 \text { to } 100) \\
\end{array}$ & $\begin{array}{c}55.6 \pm 43.6 \\
(0 \text { to } 100)\end{array}$ & $\begin{array}{c}71.95 \pm 19.4 \\
(0 \text { to } 96)\end{array}$ \\
\hline Post-op & $\begin{array}{l}89 \pm 11.5 \\
(65 \text { to } 100)\end{array}$ & $\begin{array}{c}77.4 \pm 37.8 \\
(0 \text { to } 100)\end{array}$ & $\begin{array}{l}74 \pm 22.3 \\
(20 \text { to } 90) \\
\end{array}$ & $\begin{array}{c}72.6 \pm 13.8 \\
(45 \text { to } 85) \\
\end{array}$ & $\begin{array}{l}82.6 \pm 9.7 \\
(55 \text { to } 100)\end{array}$ & $\begin{array}{l}81.5 \pm 15.6 \\
(50 \text { to } 100)\end{array}$ & $\begin{array}{c}82.5 \pm 32.7 \\
(0 \text { to } 100)\end{array}$ & $\begin{array}{l}90.4 \pm 7.62 \\
(80 \text { to } 100)\end{array}$ \\
\hline$p$ value & $<0.01$ & $<0.01$ & $<0.01$ & 0.2 & $<0.01$ & 1 & $<0.01$ & $<0.01$ \\
\hline
\end{tabular}

results of Sf-36 are subdivided according to the coverage areas. The detailed results can be found in table 3. As complications, we had one case with superficial infection, showing improvement after one week of oral antibiotic therapy. Two cases had a small fracture of the coracoid at the time of osteotomy losing the fixation of the superior endobutton, however, as the inferior endobutton gave good stability to the fragment, no additional procedure was necessary. Two patients had postoperative graft migration with no progression to further instability, no need for further surgical intervention. We did not observe any neurological lesion or recurrent instability.

\section{DISCUSSION}

The results found in this study are similar to those of other publications. We observed improvement in all the functional scores and no cases of recurrent instability were reported. The procedure was effective eliminating the symptomatology and providing an early return to daily activities. Operative techniques have recently advanced so that orthopedic shoulder surgeons can successfully perform procedures aimed at correcting anterior glenohumeral instability, regardless of whether the patient needs labrum repair or bone graft. ${ }^{8}$ Reconstruction using coracoid graft is currently recommended in Latarjet and iliac crest surgeries, for treating bone deficiency of the glenoid. Besides providing stability, the bone graft normalizes contact pressures to values similar to that of a normal shoulder. ${ }^{9}$ Technical difficulty, specific guides for the positioning of the coracoid, and the potential risks of injuring anatomical normal structures, are the main challenges of the arthroscopic Latarjet procedure, hindering the adoption of this surgical technique in some countries. ${ }^{6}$ We showed in our study that even using only an ACL guide, the results of glenoid graft positioning indexes can be as good as those obtained by studies using specific guides. ${ }^{10}$
Considering the advantages of the treatment with arthroscopic Latarjet when compared to open surgery, ${ }^{11}$ such as lesser time of recovery and identification of intra-articular pathologies, it is fundamental to promote the diffusion of techniques that are reproducible in countries with no availability of specific instruments, mainly due to their cost. Thus, the use of endobuttons is viable in performing this procedure, allowing a correct positioning of the graft and positive results in the functional scores with significant improvement. Furthermore, it is possible to address other lesions at the time of surgery, which was necessary for $42 \%$ of the patients. The Latarjet technique combined with endobutton, uses instruments widely available in hospitals, and its easy to perform after the proper learning curve. Similarly, to other authors, we observed that some complications were associated with the learning curve, showing complications described earlier. ${ }^{12}$ These complications may have occurred due to the wrong choice of positioning of the coracoid bone tunnel; however, with the improvement in surgical technique, this event ceased to occur. Thus, we believe that this technique with endobutton is reproducible and does not require additional

instruments. A great advantage of the Latarjet technique combined with endobuttons is that the tunnels, which are created from the posterior to the anterior region, facilitate the correct positioning in relation to vascular-nervous structures, which may cause incorrect inclination when fixation is made using screws.

\section{CONCLUSION}

Surgical treatment using the arthroscopic Latarjet technique combined with endobuttons for the treatment of anterior instability of the shoulder showed good results in terms of functional outcomes. The technique is effective, safe, and provides early rehabilitation.

AUTHORS' CONTRIBUTIONS: Each author made significant individual contributions to this manuscript. ATN (0000-0003-3044-959X)* GKC (0000-0002$9830-754 \mathrm{X})^{\star}, \mathrm{PBR}(0000-0001-5089-1022)^{\star}, \mathrm{JPZ}(0000-0001-5941-7714)^{\star}, \mathrm{OPC}(0000-0002-1128-7292)^{*}$, were the main contributors in writing this work ATN participated in: research, design, writing and data collection; GKC participated in: concept, research, writing and data collection; PBR participated in: concept, research, writing and data collection; JPZ participated in: writing, concept, design, and analysis; OPC participated in: concept, writing and analysis. ${ }^{*}$ ORCID (Open Researcher and Contributor ID).

\section{REFERENCES}

1. Provencher MT, Bhatia S, Ghodadra NS, Grumet RC, Bach BR Jr, Dewing CB, et al. Recurrent shoulder instability: Current concepts for evaluation and management of glenoid bone loss. J Bone Joint Surg Am. 2010;92(Suppl 2):133-51.

2. Sayegh ET, Mascarenhas R, Chalmers PN, Cole BJ, Verma NN, Romeo AA. Allograft reconstruction for glenoid bone loss in glenohumeral instability: A systematic review. Arthroscopy. 2014;30(12):1642-9.

3. Freedman KB, Smith AP, Romeo AA, Cole BJ, Bach BR Jr. Open Bankart repair versus arthroscopic repair with transglenoid sutures or bioabsorbable tacks for recurrent anterior instability of the shoulder: a meta-analysis. Am J Sports Med. 2004;32(6): 1520-7.

4. Kempf JF, Lacaze F, Hila A. [Anterior instability and hyperlaxity of the shoulder] Rev Chir Orthop Reparatrice Appar Mot. 2000;86(Suppl 1):132-7.

5. Lafosse L, Torres J. Procedimento de Latarjet artroscópico: Indicações, técnica e resultados. Rev Port Ortop Traum. 2012;20(1):5-19.

6. Gracitelli ME, Ferreira AA, Benegas E, Malavolta EA, Sunada EE, Assunção $\mathrm{JH}$. Arthroscopic latarjet procedure: safety evaluation in cadavers. Acta Ortop Bras. 2013;21(3):139-43.
7. Taverna E, D'Ambrosi R, Perfetti C, Garavaglia G. Arthroscopic bone graft procedure for anterior inferior glenohumeral instability. Arthrosc Tech. 2014;3(6):e653-60.

8. Kim SJ, Kim SH, Park BK, Chun YM. Arthroscopic stabilization for recurrent shoulder instability with moderate glenoid bone defect in patients with moderate to low functional demand. Arthroscopy. 2014;30(8):921-7.

9. Greis PE, Scuderi MG, Mohr A, Bachus KN, Burks RT. Glenohumeral articular contact areas and pressures following labral and osseous injury to the anteroinferior quadrant of the glenoid. J Shoulder Elbow Surg. 2002;11(5):442-51.

10. Boileau P, Gendre P, Baba M, Thélu CÉ, Baring T, Gonzalez JF, et al. A guided surgical approach and novel fixation method for arthroscopic Latarjet. J Shoulder Elbow Surg. 2016;25(1):78-89.

11. Arrigoni P, Huberty D, Brady PC, Weber IC, Burkhart SS. The value of arthroscopy before an open modified latarjet reconstruction. Arthroscopy. 2008;24(5):514-9

12. Bonnevialle N, Thélu CE, Bouju Y, Vogels J, Agout C, Duriez P, et al. Arthroscopic Latarjet procedure with double-button fixation: short-term complications and learning curve analysis. J Shoulder Elbow Surg. 2018;27(6):e189-95. 